\title{
Characterization of a Legionella pneumophila gene encoding a lipoprotein antigen
}

N. C. Engleberg, ${ }^{1,2 *}$ D. C. Howe, ${ }^{2}$ J. E. Rogers, ${ }^{2}$ J. Arroyo $^{2}$ and B. I. Eisenstein ${ }^{1,2}$

${ }^{1}$ Department of Internal Medicine, and ${ }^{2}$ Department of Microbiology and Immunology, University of Michigan Medical School, Ann Arbor, Michigan 48109-0620, USA.

\section{Summary}

A prominent $19 \mathrm{kDa}$ surface antigen of Legionella pneumophila, cloned in Escherichia coli, was found to be intimately associated with peptidoglycan. The DNA region encoding this antigen was mapped on an $11.9 \mathrm{~kb}$ plasmid by means of deletion analysis and transposon mutagenesis. PhoA ${ }^{+}$gene fusions, generated by TnphoA insertions into this region, confirmed the presence of a gene encoding a secreted protein. $\mathrm{PhoA}^{+}$transposon insertions were also associated with loss of the $19 \mathrm{kDa}$ antigen in immunoassays using a monoclonal antibody (mAb1E9) and the replacement of the $19 \mathrm{kDa}$ antigen with larger fusion proteins in immunoblots using Legionella immune serum. A 1540 bp PstI fragment carrying the gene was sequenced, and the open reading frame encoding the antigen was identified. The gene encodes a polypeptide 176 amino acid residues long and 18913 Da in size. The presence of a signal sequence of 22 amino acids with a consensus sequence for cleavage by signal peptidase II indicates that the antigen is a lipoprotein, and striking similarity with peptidoglycan-associated lipoproteins (PALs) from E. coli (51\% amino acid homology) and Haemophilus influenzae ( $55 \%$ homology) is noted. We conclude that the $19 \mathrm{kDa}$ antigen of L. pneumophila is the structural equivalent of the PAL found in other Gram-negative species and suggest that its post-translational acylation may explain its potency as an immunogen.

\section{Introduction}

We previously described the cloning of a $19000 \mathrm{Da}$ (19kDa) antigen of Legionella pneumophila and subsequently showed that this protein is accessible to serum

Received 26 February, 1991; revised 22 May, 1991. "For correspondence. Tel. (313) 936 0879; Fax (313) 7643562. antibodies on the surface of both L. pneumophila and Escherichia coli clones carrying the gene for this antigen on a multicopy plasmid, pSMJ11 (Engleberg et al., 198$4 a, b)$. All $L$. pneumophila strains that we have tested express this antigen, and strains of several other Legionella species express a smaller, cross-reactive protein of $\sim 18 \mathrm{kDa}$ (Engleberg et al., 1986). In polyacrylamide gels, the $19 \mathrm{kDa} L$. pneumophila antigen nearly comigrates with the $E$. coli peptidoglycan-associated lipoprotein (PAL). Both the L. pneumophila protein and the comigrating $E$. coli PAL produce a 'tailing' phenomenon in polyacrylamide gels that is typically associated with lipoproteins. Peptidoglycan-associated lipoproteins similar to the $E$. coli PAL have been identified in several Gram-negative bacterial species (Mizuno, 1981; Deich et al., 1990), and we hypothesized that the $18-19 \mathrm{kDa}$ Legionella antigens might be homologues of these lipoproteins.

Although the functional role of the small, peptidoglycanassociated lipoproteins remains unproven, it is assumed that these molecules have a structural role, providing anchorage between the cell wall and the outer membrane. These molecules are of interest in pathogenic bacteria, because they may be potent B-cell mitogens and immunoadjuvants (Melchers et al., 1975; Lex et al., 1986). Moreover, because they are primarily localized to the outer membrane, they may be accessible to specific antibodies on the bacterial surface. The Haemophilus influenzae PAL has been shown to be a target for bactericidal antibodies and may be regarded as a potential vaccine candidate (Green et al., 1987).

In this communication we present the DNA sequence of the $19 \mathrm{kDa}$ L. pneumophila antigen gene. Its inferred amino acid sequence data confirm the presence of a signal for acylation and a high degree of amino acid homology with other known PAL sequences. We conclude that this protein is a homologue of the previously sequenced $E$. coli and $H$. influenzae pal genes (Chen and Henning, 1987; Deich et al., 1990).

\section{Results}

\section{Peptidoglycan association of the $19 \mathrm{kDa}$ antigen}

In a previous study, we showed that the L. pneumophila major outer membrane protein (MOMP) is peptidoglycanbound by first heating bacteria in $2 \%$ sodium dodecyl 


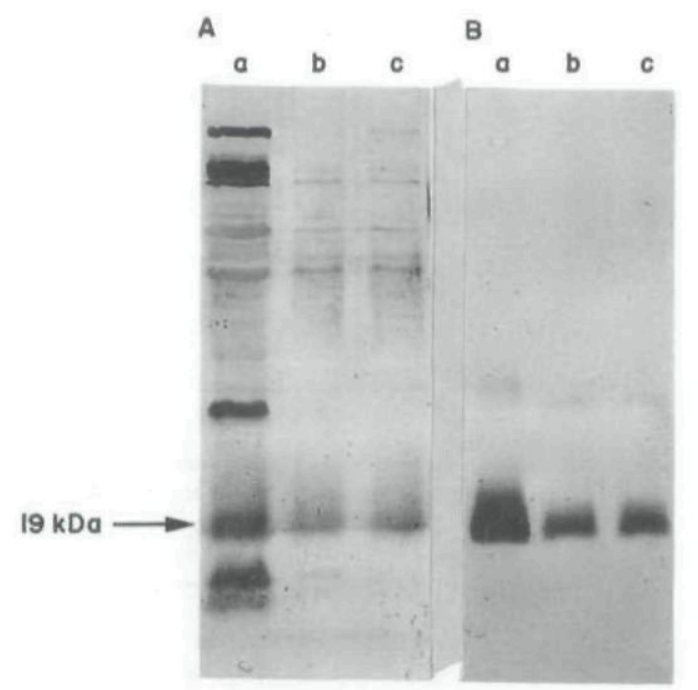

Fig. 1. Immunoblots of solubilized proteins from L pneumophila AA100. Identical immunoblots were probed with either $L$. micdadei immune serum (panel A) or mAb1E9 (panel B). L. micdadei antiserum was used in this experiment to minimize background and to limit the number of visualized antigens. Immunoblots of bacterial lysates with homologous antisera produce a background reactivity with lipopolysaccharide (LPS). $L$ micdadei antiserum has no detectable LPS cross-reactivity, but it has strong cross-reactivity with the $19 \mathrm{kDa}$ antigen and several other $L$. pneumophila proteins. Lanes: a, supernatant from bacteria boiled in $2 \%$ SDS for $2 \mathrm{~min} ; \mathrm{b}$, insoluble pellet from lane a samples washed and reboiled in $2 \%$ SDS for $5 \mathrm{~min}$; $\mathrm{c}$, insoluble pellet washed and reboiled in $4 \%$ SDS for $5 \mathrm{~min}$.

sulphate (SDS) for $2 \mathrm{~min}$, recovering the insoluble pellet by centrifugation, and subsequently releasing the MOMP from the pellet by reheating to $100^{\circ} \mathrm{C}$ for $10 \mathrm{~min}$ in $2 \% \mathrm{SDS}$ with 5\% 2-mercaptoethanol (Engelberg et al., 1989). In that experiment, immunoblots of the peptidoglycan-associated proteins with Legionella immune serum showed that the predominant antigen released from the insoluble pellet was $19 \mathrm{kDa}$ in size. To confirm that this peptidoglycan-associated antigen is identical to the one encoded on pSMJ11, we repeated this experiment and immunoblotted the peptidoglycan-associated fraction with immune sera and with a monoclonal antibody (mAb1E9) that reacts with the cloned antigen. The immunoblot shown in Fig. 1 confirms that much of the $19 \mathrm{kDa}$ antigen is associated with peptidoglycan, since a significant proportion is retained with the insoluble pellet after most other bacterial proteins are solubilized. The reactivity of the antigen with mAb1E9 in both soluble and insoluble fractions confirms the identity of this protein.

\section{Subcloning of the $19 \mathrm{kDa}$ antigen gene}

The $19 \mathrm{kDa}$ antigen was originally cloned on plasmid pSMJ11 (Engleberg et al., 1984a). Various restriction fragments were deleted from the insert in pSMJ11, and the resulting clones were tested for expression of the $19 \mathrm{kDa}$ antigen (Fig. 2A). The $\sim 3.75 \mathrm{~kb}$ insert of pSMJ11. 4 was the smallest of the fragments that still expressed the antigen. Either of two deletions within the pSMJ11.4 insert (made at unique Sphl and Aval sites using S1 nuclease digestion and blunt-end ligation) abrogated expression of the $19 \mathrm{kDa}$ antigen, suggesting that these mutations may disrupt a reading frame that is critical for antigen expression.

To be able, eventually, to mobilize the cloned gene from E. coli into L. pneumophila, the insert expressing the $19 \mathrm{kDa}$ antigen was cloned into a vector with an antibiotic resistance marker that is selectable in $L$. pneumophila, i.e. pTLP5 (chloramphenicol-resistant, $\mathrm{Cm}^{\mathrm{R}}$; streptomycinsensitive, $\mathrm{Sm}^{\mathrm{S}}$ ). Accordingly, the EcoRI-Pvull fragment of pSMJ11.4 was first ligated to pUC18 digested with EcoRI and Smal. This manipulation allowed for the positioning of the BamHI site of the pUC18 multiple cloning site next to the Pvull-Smal junction at which the insert and vector are joined. The large Bam $\mathrm{HI}-\mathrm{BC} / \mathrm{l}$ fragment of this intermediate plasmid was then isolated and cloned into the unique Bam HI site of pTLP5 to yield pDH11.2. Immunoblotting experiments confirmed that the $19 \mathrm{kDa}$ antigen is expressed from $\mathrm{pDH} 11.2$ to the same degree as from pSMJ11.4 (data not shown).

\section{Mutagenesis of a DNA fragment encoding the $19 \mathrm{kDa}$ antigen with TnphoA}

In initial experiments with transpositional mutagenesis, TnphoA-1 was inserted into the fragment of interest on pSMJ11.4. In later experiments, TnphoA-oriT was inserted into the slightly shorter fragment on pDH11.2. This second set of transposon insertions was generated in anticipation of future experiments (now in progress) in which the mutated genes on these plasmids will be transferred to $L$. pneumophila and exchanged for the native genes. In all transposition experiments, E. coli CC118 carrying the relevant plasmid was infected with either $\lambda$ TnphoA-1 or $\lambda::$ TnphoA-oriT and plated on LB/XP media containing kanamycin $\left(200\right.$ or $\left.300 \mu \mathrm{g} \mathrm{ml}^{-1}\right)$. Plasmid minipreps were prepared from individual transductants that appeared blue (i.e. $\mathrm{PhoA}^{+}$) and were used to retransform strain $\mathrm{CC} 118$. If the transconjugants were all $\mathrm{PhoA}^{+}$on media with XP, then the plasmid was assumed to have acquired a phosphatase function and was analysed using restriction endonucleases. Each transposition yielding a PhoA fusion was designated by the letter $\mathrm{B}$ (for 'blue') followed by an individual number (given in Fig. 2B). Several kanamycin-resistant transductants that were $\mathrm{PhoA}^{-}$were likewise analysed to identify random TnphoAoriT insertions in pDH11.2. These transpositions were designated by the letter W (for 'white') followed by an individual number. 
A

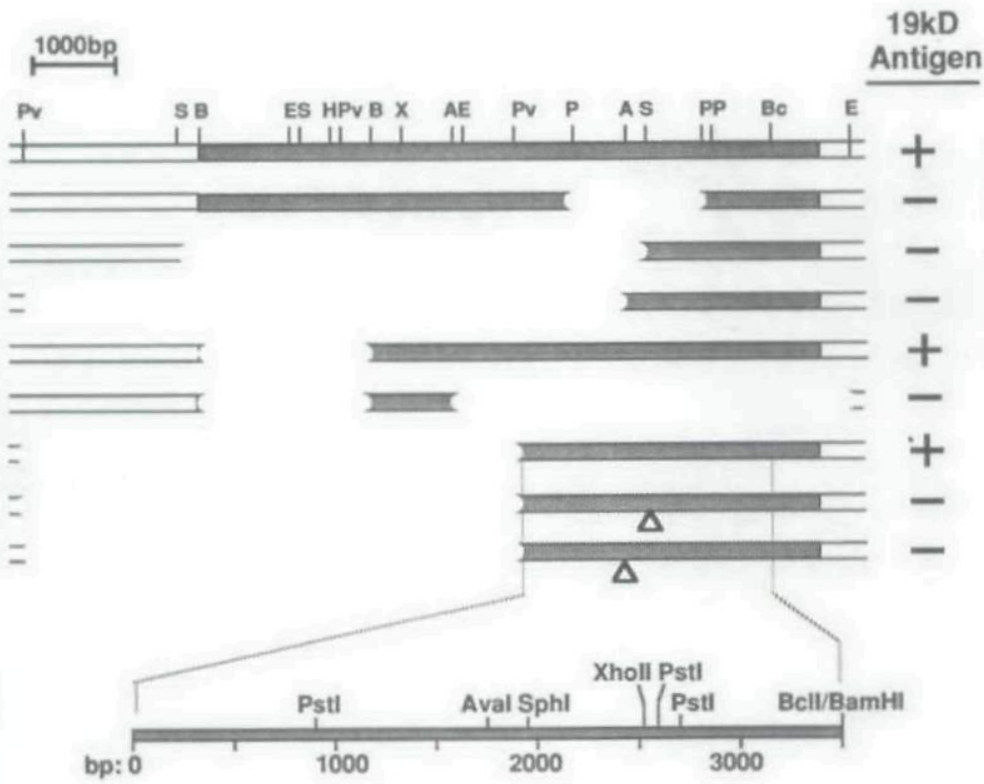

Fig. 2. Analysis of pSMJ11 subclones and their expression of the $19 \mathrm{kDa}$ antigen.

A. The shaded areas of the linearized map (above) represent the insert of L. pneumophila DNA; the unshaded portions represent relevant sections of the vector, pBR322. The triangles represent localized deletions made by endonuclease digestion at the specified site, S1 nuclease treatment, repair with Klenow fragment. and blunt-end ligation. The column at the right indicates whether a $19 \mathrm{kDa}$ antigen was seen on Western blots of the strains carrying the respective deletion.

B. A restriction map of the region cloned in pSMJ11.4 and pDH11.2 is shown with the position of TnphoA-orit insertions below. The direction of the phoA reading frame is indicated by an arrow over each transposition marker. For reference purposes, the numerical designation for each transposition is given (see text concerning nomenclature). Note that the region from position 600 to 1200 is entirely free of transpositions. C. Potential open reading frames deduced from the sequence of the large Pstl fragment are indicated by the open arrows below the map.

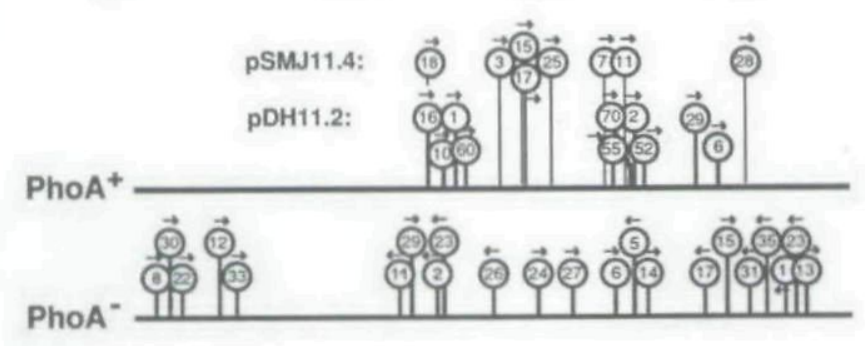

C

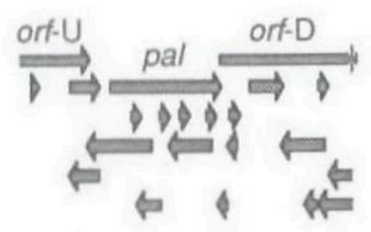

Within the $\sim 3500 \mathrm{bp}$ insert of pSMJ11.4 and pDH11.2, $\mathrm{PhoA}^{+}$gene fusions were limited to $\mathrm{a} \sim 1600 \mathrm{bp}$ region, and all transpositions giving productive fusions were oriented in the same direction (Fig. 2B). Several of these transpositions were clustered near the Aval and Sphl sites, previously shown to be critical for the expression of the $19 \mathrm{kDa}$ antigen. Clones carrying transpositions B-16, B-17, and all transpositions between, failed to react with mAb1E9 by dot immunoblot analysis. In addition, Western blot analysis of some of these clones using Legionella immune serum showed that the $19 \mathrm{kDa}$ antigen was absent and that new antigenic bands of $>47 \mathrm{~kb}$, presumably fusion proteins, were present instead (Fig. 3, panel A). Fusions downstream of B-17 did not affect expression of the $19 \mathrm{kDa}$ antigen. We inferred from these findings that the region defined by gene fusions B-16 to B-17 represents the gene encoding the $19 \mathrm{kDa}$ antigen.
An additional cluster of $\mathrm{PhoA}^{+}$fusions was mapped to a $\sim 1000$ bp region immediately downstream from the $19 \mathrm{kDa}$ antigen gene (Fig. $2 \mathrm{~B}$ ). The clones carrying the fùsions from B-25 to B-28 were reactive with $\mathrm{AAb} 1 \mathrm{E} 9$ and all of those tested expressed the $19 \mathrm{kDa}$ antigen on Western blots with Legionella immune serum. Western blot analysis of several of these clones with alkaline phosphatase antiserum showed fusion products of increasing size (from $\sim 69$ to $\sim 88 \mathrm{kDa}$ ) corresponding to the point of the transposon insertion, i.e. as the transposon insertions mapped further downstream, the fusion products were larger (Fig. 3, panel B). This analysis suggests that the cloned region immediately downstream from the $19 \mathrm{kDa}$ antigen gene contains another gene encoding a single secreted protein.

Finally, 22 TnphoA-oriT transpositions that did not produce gene fusions were mapped within the $\mathrm{pDH} 11.2$ 
A

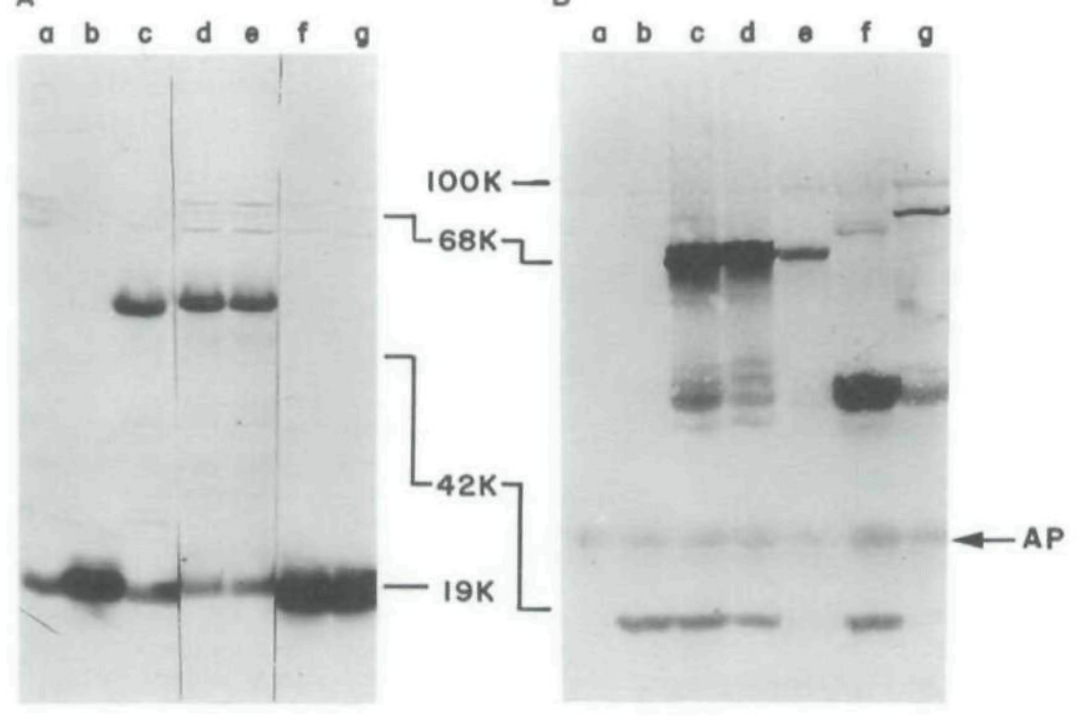

Fig. 3. Immunoblots of strains carrying TnphoA oriT gene fusions in the DNA fragment encoding the $19 \mathrm{kDa}$ antigen.

A. Immunoblot with L. pneumophila immune serum. Lane a, E. coli control; lane b. E. coli (pSMJ11.4); lanes c-g. TnphoA transpositions in pSMJ11.4, B-3, B-15, B-17, B-7, and B-11. Note the weak reactivity of the rabbit serum with a comigrating $19 \mathrm{kDa}$ antigen in E. coli.

B. Immunoblot with alkaline phosphatase antiserum. Lane a, E. coli control; lane b, E. coli (pDH11.2::B-55); lanes c-g. TnphoA-oriT transpositions in pDH11.2, B-70, B-2, B-52, B-29, and B-6. The mobilities of prestained molecular weight markers are indicated. AP, native E. coli alkaline phosphatase monomer. insert fragment (Fig. 2B). These transpositions were randomly distributed within the fragment, except for a region of $\sim 750 \mathrm{bp}$ immediately upstream of the $19 \mathrm{kDa}$ antigen gene, into which no transpositions were isolated.

\section{DNA sequence of the $19 \mathrm{kDa}$ protein antigen}

The two Sphl-Pstl fragments representing the upstream and downstream portions of the $19 \mathrm{kDa}$ antigen gene, as well as a Sau3A fragment that spans the internal SphI site, were isolated and cloned into the replicative form of both M13mp18 and M13mp19. Single-stranded templates of the resulting phages were purified and sequenced as described below. The first $140 \mathrm{bp}$ of sequence are derived from a single strand and therefore should be considered tentative. All remaining portions of the sequence were derived from primer extension on both strands using overlapping templates.

The DNA sequence obtained from these $\mathrm{M} 13$ subclones is shown in Fig. 4. Three long open reading frames were identified, all of which would be transcribed in the same direction as the TnphoA gene fusions. One of the open reading frames $(528 \mathrm{bp})$ spans the region to which the $19 \mathrm{kDa}$ antigen gene was mapped (Fig. 2C). An upstream open reading frame (orfU) of at least $309 \mathrm{bp}$ begins upstream of the boundary of the sequenced fragment and terminates $101 \mathrm{bp}$ before the beginning of the $19 \mathrm{kDa}$ gene. A downstream open reading frame (orfD) of at least $613 \mathrm{bp}$ begins $1 \mathrm{bp}$ before the termination codon of the $19 \mathrm{kDa}$ antigen gene (i.e. the sequence is ... ATGA ...) and extends beyond the boundary of the subcloned fragment.

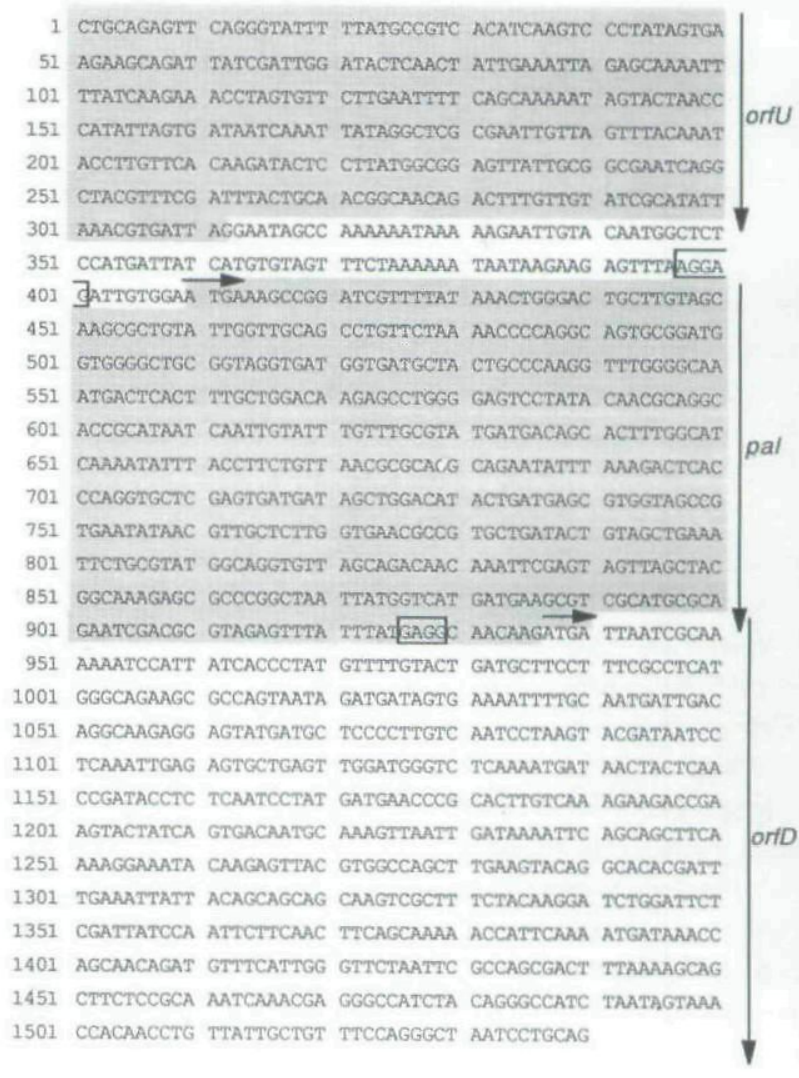

Fig. 4. DNA sequence of $1540 \mathrm{bp}$ encoding the $19 \mathrm{kDa}$ antigen of $L$. pneumophila. The positions of the three large open reading frames are indicated on the right, with arrows indicating the initiation codons of pal and orfD. Putative Shine-Dalgarno sequences associated with the translational starts are indicated by boxes. These sequence data will appear in the EMBL/GenBank/DDBJ Nucleotide Sequence Data Libraries under the accession number X60543. 
gene and the $3^{\prime}$ end of orf (Fig. 2B) by ligating it into the pBR322 derivative, pJA1, after digestion with $\mathrm{BamHI}$ and Nsil. After several attempts to do this had failed, we repeated the ligation reaction and then transformed competent E. coli HB101 and HB101(pDH11.2::TnphoAoriT.B-16) in parallel. Phenotypically, the latter strain is $\mathrm{Km}^{\mathrm{R}}$ (kanamycin-resistant), $\mathrm{Cm}^{\mathrm{R}}$, $\mathrm{PhoA}^{+}$, and $\mathrm{PAL}^{-}$, and the plasmid (which we will abbreviate in further references as ( $\mathrm{pDH} 11.2:: \mathrm{B}-16$ ') includes an intact orf $\mathrm{U}$ region. As expected, there were no ampicillin-resistant $\left(\mathrm{Ap}^{\mathrm{P}}\right)$ transformants of HB101; however, using the same amount of the same ligation mixture, there were $53 \mathrm{Ap}^{\mathrm{R}}$ transformants of HB101(pDH11.2::B-16), two of which were also $\mathrm{PAL}^{+}$. One of the $\mathrm{PAL}^{+}$isolates contained two plasmids: one was the size of $\mathrm{pDH} 11.2: \mathrm{B}-16$, and the other was the size predicted for the pJA1-pal hybrid plasmid. When this isolate was passed on streptomycincontaining media to counterselect pDH11.2::B-16 (which carries $r p s L\left(\mathrm{Sm}^{S}\right)$ allele), 30 colonies were screened and found to be $\mathrm{Cm}^{\mathrm{s}}, \mathrm{Km}^{\mathrm{R}}$, and $\mathrm{Ap}^{\mathrm{R}}$; all 30 were $\mathrm{PAL}^{+}$. The original $\mathrm{PAL}^{+}$isolate and the $\mathrm{Sm}^{\mathrm{R}}$ isolates were unstable and became $\mathrm{PAL}^{-}$with passage, in spite of continued selective pressure with ampicillin, and they lost all detectable plasmid DNA. The second of the two $\mathrm{PAL}^{+}$transformants carried a single plasmid intermediate in size between pDH11.2::B-16 and the pJA1-pal hybrid. Streptomycin-resistant derivatives from this isolate were $\mathrm{Cm}^{\mathrm{s}}$, $\mathrm{Km}^{\mathrm{S}}, \mathrm{Ap}^{\mathrm{R}}$, and $\mathrm{PAL}^{+}$. This isolate and its derivatives were also highly unstable with respect to PAL reactivity and continued presence of plasmid DNA.

\section{Discussion}

These studies demonstrate that the $19 \mathrm{kDa}$ surface antigen is the peptidoglycan-associated lipoprotein of $L$. pneumophila. The label 'peptidoglycan-associated lipoprotein' was first applied to certain matrix proteins of Pseudomonas aeruginosa and E. coli (Mizuno, 1979). These molecules were characterized by their retention on the cell wall in $2 \%$ SDS at $35^{\circ} \mathrm{C}$, by labelling with $\left[{ }^{14} \mathrm{C}\right]$-palmitic acid and $2-\left[{ }^{3} \mathrm{H}\right]$-glycerol, and by biochemical separation from the covalently bound mureinlipoprotein described by Braun (Mizuno, 1979; Braun, 1975). Subsequently, similar lipoproteins were found in Proteus mirabilis and a wide variety of Gram-negative organisms (Mizuno, 1981). Even before DNA sequencing, we suspected that this was also the identify of the $L$. pneumophila $19 \mathrm{kDa}$ antigen because of its comigration of the $E$. coli PAL, the non-covalent but strong association with the cell wall, and the tailing phenomenon associated with this protein band in Western blots.

DNA sequencing was directed at a small region of the cloned insert of pSMJ11 that had been identified as the gene encoding the antigen by deletion analysis and transposon mutagenesis. The isolation of $\mathrm{PhoA}^{+}$fusions within this gene again confirmed that its product is a secreted polypeptide. An open reading frame, beginning with a consensus initiation codon, was found in the appropriate map position and correct orientation.

The sequence of the putative open reading frame encodes a protein with extensive homology to the pal genes of both $E$. coli and $H$. influenzae. The degree of homology is roughly comparable between any of the three sequences, particularly in the $C$-terminal half of the protein that is known to include the peptidoglycan-binding domain (Mizuno et al., 1982). In addition, the L. pneumophila protein begins with a signal sequence of 22 residues that ends with a consensus cleavage site for signal peptidase II. The presence of these features in an amino acid sequence has been generally considered sufficient evidence to characterize the sequence as a lipoprotein (Hayashi and Wu, 1990). This finding, combined with the physical characteristics of the protein and the sequence homology, leave no doubt as to its identity as the $L$. pneumophila PAL.

PAL is one of the most potent immunogens of $L$. pneumophila. Its prominence as an antigen probably explains why it was so readily cloned in our early experiments and in experiments by others who also screened an E. coli genomic library with Legionella immune serum. The reason for its immunogenicity may relate to its lipoproteinaceous nature. The Braun lipoprotein has long been known to be a B-cell mitogen (Melchers et al., 1975), and its mitogenicity can be reproduced by various synthetic lipopeptides that mimic its $\mathrm{N}$-terminus (Wiesmuller et al., 1983). The synthetic analogues differ from lipoprotein $\mathrm{N}$-termini only in that their lipid components are uniformly composed of palmitic acid. The tripalmitoyl dipeptide $N$-palmitoyl-S- (2,3-bis(palmitoyloxy) - (2RS) -propyl)-(R)cysteine-serine (or $\mathrm{Pam}_{\mathrm{s}}-\mathrm{Cys}-\mathrm{Ser}$ ) is as potent a polyclonal B-cell activator as longer lipopeptide analogues (Prass et al., 1987). This is noteworthy since this lipopeptide may also mimic the $\mathrm{N}$-terminus of the $\mathrm{L}$. pneumophila PAL.

In addition to their mitogenicity, synthetic lipopeptide analogues have also been shown to act as potent immunoadjuvants (Lex et al., 1986). A significant adjuvant effect was recently demonstrated for the lipotripeptide $\mathrm{Pam}_{3}$-Cys-Ser-Lys-, covalently bound to the hapten, dinitrophenol (Reitermann et al., 1989). Again, this analogue mimics the $L$. pneumophila PAL sequence. Similar synthetic analogues have been shown to activate macrophages and to induce the production of IL-1, IL-6, and TNF $\alpha$ (Hauschildt et al., 1990).

The implications of these lipoprotein properties for bacterial infections are speculative. However, immunogenic surface proteins from a variety of pathogenic bacteria are now known to be lipoproteins. These include the $\mathrm{H} .8$ outer membrane protein of the pathogenic 
Neisseria species (Cannon, 1989), the P6 protein (or PAL) of $H$. influenzae (Murphy et al., 1986), the Braun lipoprotein analogue of Brucella abortus (Gomez-Miguel et al., 1988), OspA and OspB of Borrelia burgdorferi (Bergstrom et al., 1989 ), and the $34 \mathrm{kDa}$ membrane protein of Treponema pallidum (Swancutt et al., 1990). The H. influenzae PAL has been shown to be a target for bactericidal antibody, even in type b encapsulated strains (Green et al., 1987). This conserved molecule is therefore a potential vaccine candidate. Likewise, monoclonal antipodies directed against this PAL have been useful in non-culture diagnostic methods for $H$. influenzae (Groeneveld et al., 1989). Whether or not the L. pneumophila PAL will prove similarly useful for preventive or diagnostic use against Legionnaires' disease is open to investigation.

The upstream partial open reading frame, which we have temporarily designated as orf $U$, seems to be required for the maintenance of $p a l$ in multiple copies. We were never able to isolate a transposition into this gene on a plasmid that contains pal, and we were never successful in cloning pal apart from orfU. We succeeded in isolating orfU and pal to separate replicons in the same strain; however, these constructs were exceedingly unstable. We speculate that $E$. coli may not tolerate multiple, isolated copies of $\mathrm{pal}$ and that the orfU region may exert a necessary moderating effect, e.g. by encoding a negative transcriptional regulator or a protein that effects PAL at the post-translational level. Transcriptional analysis of $p a /$ will resolve this issue.

It is unknown whether PAL has a role in the pathogenesis of Legionnaires' disease. As a possible mitogen and immunoadjuvant, it may influence disease by modulating the immune response. Alternatively, certain bacterial membrane lipoproteins, e.g. TraT, have been found to interfere with complement deposition, increase bacterial serum resistance, and marginally improve the growth of Salmonella typhimurium in a mouse model of infection (Rhen and Sukupolvi, 1988). More recently, genes encoding membrane lipoproteins that confer serum resistance in Vibrio cholerae were found to be activated by the global regulator of virulence in that species (ToxR; Parsot et al., 1991). Whether or not PAL participates in serum resistance of $L$. pneumophila or in other aspects of virulence is entirely speculative, but these questions might be addressed by generating isogenic $\mathrm{pal}^{-}$mutants or by manipulating the expression of PAL in L. pneumophila. In this study, several transferable plasmids were constructed with insertion mutations in pal or orfD that can be used for allelic exchange experiments in L. pneumophila.

\section{Experimental procedures}

Bacterial and plasmids

L. pneumophila AA100 is a clinical isolate that retains a high level of virulence for cultured macrophages and guinea-pigs. $L$. pneumophila AA103 is a nalidixic acid- and streptomycin-resistant derivative of AA100. L. pneumophila strains were grown on buffered charcoal yeast extract agar supplemented with $\alpha$-ketoglutarate (BCYE- $\alpha$ ) (Edelstein, 1982).

E. coli LE392 (supE, supF) was used to propagate bacteriophage $\lambda 431$ (b221, cl857, $P_{\text {am }}$ ) carrying either TnphoA (i.e. $\lambda$ TnphoA-1) or TnphoA-oriT. RecA ${ }^{-}$E. colistrains HB101 and CC118 were used for most cloning experiments. CC118 has deletion phoAL20 (Manoil and Beckwith, 1985). dam - E. coli strain K3216 (obtained from D. Friedman, University of Michigan) was used to propagate plasmids prior to performing $\mathrm{BCll}$ digestions.

pSMJ11 is a derivative of pBR322 that has a $7.5 \mathrm{~kb}$ fragment from $L$. pneumophila AA100 cloned in the BamHI site. pJA1 is a derivative of pBR322 that carries a unique multiple cloning site and which was designed and constructed in this laboratory. pTLP5 was also constructed in this laboratory (by J.A.) for the purpose of gene transfer to $L$. pneumophila. This plasmid carries the same multiple cloning site as pJA1. Further details of its construction will be reported elsewhere; however, for the purposes of this study, it is necessary to know that pTLP5 carries the chloramphenicol acetyltransferase gene of pACYC184, which is selectable in L. pneumophila, and the E. coli rpsL allele, which confers streptomycin sensitivity in L. pneumophila strain AA103.

TnphoA-oriT was generated by insertion of an origin of transfer from the IncP group of conjugative plasmids into the BamHI site of TnphoA (Manoil and Beckwith, 1985); this insertion inactivates the cryptic $\mathrm{Sm}^{\text {R }}$ gene of TnphoA. Details of this construction will be presented elsewhere (J. Arroyo, in preparation). PhoA fusions were screened by growing colonies on LB media with $40 \mu \mathrm{g} \mathrm{ml}^{-1}$ of 5-bromo-4-choro-3-indolyl phosphate (XP).

\section{Antibodies and sera}

Rabbit antisera were prepared by subcutaneous injection with heat-killed $L$. pneumophila or $L$. micdadei at biweekly intervals for 8 weeks. Anti-alkaline phosphatase serum was prepared by injection of $E$. coli alkaline phosphatase (Sigma Chemical Co.) in complete Freund's adjuvant initially and in incomplete Freund's adjuvant for booster immunizations.

Monoclonal antibody $1 \mathrm{E9}$ is a mouse monoclonal antibody generated by immunization with crude outer membrane fractions of $L$. pneumophila. To avoid production of antibodies to lipopolysaccharide, fractions for booster immunizations were isolated from $L$. pneumophila of diverse serogroups. Reactivity of mAb$1 \mathrm{E} 9$ with the native and cloned PAL antigen from AA100 was confirmed by immunoblotting; mAb1E9 also reacts with a $19 \mathrm{kDa}$ antigen in other $L$. pneumophila strains representing serogroups $1-8$, but has no reactivity with any proteins of $L$. micdadei or $E$. coli, by immunoblot analysis or dot immunoassay of whole bacteria.

\section{Gel electrophoresis and immunoblotting}

Bacterial pellets were lysed and proteins were solubilized by boiling in 2\% SDS, 5\% 2-mercaptoethanol, $50 \mathrm{mM}$ Tris- $\mathrm{HCl}(\mathrm{pH}$ 6.8) for 2-5 min in different experiments. Insoluble material was removed by centrifugation at $12000 \times g$ for $5 \mathrm{~min}$ before loading of samples. In experiments requiring re-extraction of the cell-wall 
material, the insoluble pellet was washed once in water, then re-extracted as described.

SDS lysates were separated by polyacrylamide gel electrophoresis (Laemmli, 1970). Proteins were electrotransferred to nitrocellulose membranes over $3 \mathrm{~h}$ at 40 volts in Tris-glycine buffer with $20 \%$ methanol ( $\mathrm{pH}$ 8.3). Enzyme immunoassays were performed on blots in $50 \mathrm{mM}$ Tris-buffered saline ( $\mathrm{pH} 7.5$ ) with $0.05 \%$ Tween-20 (T-TBS). T-TBS was made with $500 \mathrm{mM} \mathrm{NaCl}$ for assays with immune serum and at $150 \mathrm{mM} \mathrm{NaCl}$ for assay with mAb1E9. After one hour of blocking in T-TBS, diluted immune sera or neat mAb1E9 hybridoma supernatants were incubated with blots overnight. After three washes in T-TBS, blots were then incubated for one hour in horseradish peroxidase-conjugated goat anti-rabbit or anti-mouse immunoglobulins (Cappel Laboratories). After three final washes, peroxidase activity was detected using $0.06 \%$ diaminobenzidine (Sigma Chemical Co.) in $0.003 \%$ hydrogen peroxide.

\section{Subcloning}

Plasmid DNA was isolated by the alkaline lysis method (Birnboim and Doly, 1979). Restriction fragments for subcloning were isolated from agarose gels by electrophoresis onto DEAE membrane (Schleicher \& Schuell) and eluted into high-salt buffer as described (Lizardi et al., 1984). Ligation and transformation of $\mathrm{CaCl}_{2}$-treated $E$. coli were performed using standard methods (Sambrook et al., 1989).

\section{Transposon mutagenesis}

E. coli strains carrying plasmids with target sequences were transduced to kanamycin resistance with $\lambda$ TnphoA-1 or $\lambda::$ TnphoA-oriT. Plasmids were then isolated and introduced into CC118 by transformation or were transferred conjugally (in the case of TnphoA-oriT) using a helper strain with conjugative plasmid pRK212.1. If transpositions mapped to the plasmid, the plasmid was isolated by the alkaline lysis technique, and the position of the transposon was mapped with restriction endonucleases.

\section{DNA sequencing}

Sequencing of M13 templates was performed using the dideoxy chain termination method (Sanger et al., 1977). M13-based primers were used initially, but for subsequent reactions, oligonucleotide primers were synthesized. Primer extension was catalysed by Sequenase (US Biochemical). DNA and protein sequences were analysed using Microgenie and MacVector software. Searches of the National Library of Medicine Protein Data Bank were supported by both of these software packages.

\section{Acknowledgements}

The authors thank Nick Cianciotto (for assistance with the animal experiments), Janne Cannon (for helpful discussions), J. J. Mekalanos and David Friedman (for providing useful strains), and Susan Miller (for technical assistance in the laboratory). N.C.E. is supported by P.H.S. Grant No. RO1Al26232. B.I.E. is supported by P.H.S. Grant No. RO1Al24731.

\section{References}

Bergstrom, S., Bundoc, V.G., and Barbour, A.G. (1989) Molecular analysis of linear plasmid-encoded major surface proteins, OspA and OspB, of the Lyme disease spirochaete Borrelia burgdorferi. Mol Microbiol 3: 479-486.

Birnboim, H.C., and Doly, J. (1979) A rapid alkaline extraction procedure for screening recombinant plasmid DNA. Nucl Acids Res 7: 1513-1523.

Braun, V. (1975) Covalent lipoprotein from the outer membrane of Escherichia coli. Biochim Biophys Acta 415: 335-377.

Cannon, J.G. (1989) Conserved lipoproteins of pathogenic Neisseria species bearing the $\mathrm{H} .8$ epitope: lipid-modified azurin and H.8 outer membrane protein. Clin Microbiol Rev 2(Suppl.): S1-S4.

Chen, R., and Henning, U. (1987) Nucleotide sequence of the gene for the peptidoglycan-associated lipoprotein of Escherichia coli K-12. Eur J Biochem 163: 73-77.

Deich, R.A., Anilionis, A., Fulginiti, J., Metcalf, B.J., Quataert, S., Quinn-Dey, T., Zlotnick, G.W., and Green, B.A. (1990) Antigenic conservation of the 15,000-dalton outer membrane lipoprotein PCP of Haemophilus influenzae and biologic activity of antiPCP antisera. Infect Immun 58: 3388-3393.

Edelstein, P.H. (1982) Comparative study of selective media for isolation of Legionella pneumophila from potable water. J Clin Microbiol 16: 697-699.

Engleberg, N.C., Drutz, D.J., and Eisenstein, B.I. (1984a) Cloning and expression of Legionella pneumophila antigens in Escherichia coli. Infect Immun 44: 222-227.

Engleberg, N.C., Pearlman, E., and Eisenstein, B.I. (1984b) Legionella pneumophila surface antigens cloned and expressed in Escherichia coli are translocated to the host cell surface and interact with specific anti-Legionella antibodies. $J$ Bacteriol 160: 199-203.

Engleberg, N.C., Pearlman, E., Dixon, D., and Eisenstein, B.I. (1986) Antibodies isolated by using cloned surface antigens recognize antigenically related components of Legionella pneumophila and other Legionella species. J Immunol 136: 1415-1417.

Engleberg, N.C., Carter, C., Weber, D.R., Cianciotto, N.P., and Eisenstein, B.I. (1989) DNA sequence of mip, a Legionella pneumophila gene associated with macrophage infectivity. Infect Immun 57: 1263-1270.

Gomez-Miguel, M.J., Moriyon, I., Alonso-Urmeneta, B., RiezuBoj, J.I., and Diaz, R. (1988) Serologic response to the outer membrane lipoprotein in animal brucellosis. Infect Immun 56: 716-718.

Green, B.A., Quinn-Dey, T., and Zlotnick, G.W. (1987) Biologic activities of antibody to a peptidoglycan-associated lipoprotein of Haemophilus influenzae against multiple clinical isolate of $H$. influenzae type b. Infect Immun 55: 2878-2883.

Groeneveld, K., van Alphen, L., van Ketel, R.J., Geelen-van den Broek, L., Eijk, P.P., and Zanen, H.C. (1989) Nonculture detection of Haemophilus influenzae in sputum with monoclonal antibodies specific for outer membrane lipoprotein P6. $J$ Clin Microbiol 27: 2263-2267.

Hauschildt, S., Hoffmann, P., Beuscher, H.U., Dufhues, G., Heinrich, P., Wiesmuller, K.H., Jung, G., and Bessler, W.G. (1990) Activation of bone marrow-derived mouse macrophages by bacterial lipopeptide: cytokine production, phagocytosis and la expression. Eur J Immunol 20: 63-68. 
Hayashi, S., and Wu, H.C. (1990) Lipoproteins in bacteria. J Bioenerg Biomembr 22: 451-471.

Laemmli, U.K. (1970) Cleavage of structural proteins during the assembly of the head of bacteriophage T4. Nature 227: $680-685$.

Lex, A., Wiesmuller, K.H., Jung, G., and Bessler, W.G. (1986) A synthetic analogue of Escherichia coli lipoprotein, tripalmitoyl pentapeptide, constitutes a potent immune adjuvant. $J$ Immunol 137: 2676-2681.

Lizardi, P.M., Binder, R., and Short, S.A. (1984) Preparative isolation of DNA and biologically active mRNA from diethylaminoethyl membrane. Gene Anal Techn 1: 33-39.

Manoil, C., and Beckwith, J. (1985) TnphoA: a transposon probe for protein export signals. Proc Natl Acad Sci USA 82: 8129-8133.

Melchers, F., Braun, V., and Galanos, C. (1975) The lipoprotein of the outer membrane of Escherichia coli: a B-lymphocyte mitogen. J Exp Med 142: 473-482.

Mizuno, T. (1979) A novel peptidoglycan-associated lipoprotein found in the cell envelope of Pseudomonas aeruginosa and Escherichia coli. J Biochem (Tokyo) 86: 991-1000.

Mizuno, T. (1981) A novel peptidoglycan associated lipoprotein (PAL) found in the outer membrane of Proteus mirabilis and other Gram-negative bacteria. J Biochem (Tokyo) 89: 10391049.

Mizuno, T., Kagiyama, R., and Kageyama, M. (1982) The peptidoglycan-associated lipoprotein (PAL) of the Proteus mirabilis outer membrane: characterization of the peptidoglycan-associated region of PAL. J Biochem (Tokyo) 91: 19-24.

Mulligan, M.E., Hawley, D.K., Entriken, R., and McClure, W.R. (1984) Escherichia coli promoter sequences predict in vitro RNA polymerase selectivity. Nucl Acids Res 12: 789-791.

Murphy, T.F., Bartos, L.C., Rice, P.A., Nelson, M.B., Dudas, K.C., and Apicella, M.A. (1986) Identification of a 16,600 dalton outer membrane protein on nontypable Haemophilus influenzae as a target for human bactericidal antibody. $J$ Clin Invest 78: 1020-1027.

Parsot, C., Taxman, E., and Mekalanos, J.J. (1991) ToxR regulates the production of lipoproteins and the expression of serum resistance in Vibrio cholerae. Proc Nat/ Acad Sci USA 88: 1641-1645.

Prass, W., Ringsdorf, H., Bessler, W., Wiesmuller, K.-H., and Jung, G. (1987) Lipopeptides of the $\mathrm{N}$-terminus of Escherichia coli lipoprotein: synthesis, mitogenicity and properties in monolayer experiments. Biochim Biophys Acta 900: 116-128.

Reitermann, A., Metzger, J., Wiesmuller, K.H., Jung, G., and Bessier, W.G. (1989) Lipopeptide derivatives of bacterial lipoprotein constitute potent immune adjuvants combined with or covalently coupled to antigen or hapten. Biol Chem Hoppe Seyler 370: 343-352.

Rhen, M., and Sukupolvi, S. (1988) The role of the traT gene of the Salmonella typhimurium virulence plasmid for serum resistance and growth within liver macrophages. Microb Pathogen 5: 275-285.

Sambrook, J., Fritsch, E.F., and Maniatis, T. (1989) Molecular Cloning. A Laboratory Manual. Cold Spring Harbor, New York: Cold Spring Harbor Laboratory Press.

Sanger, F., Nicklen, S., and Coulson, A.R. (1977) DNA sequencing with chain-terminating inhibitors. Proc Natl Acad Sci USA 74: 5463-5467.

Stormo, G.D., Schneider, T.D., and Gold, L.M. (1982) Characterization of translational initiation sites in E. coli. Nucl Acids Res 10: 2971-3011.

Swancutt, M.A., Radolf, J.D., and Norgard, M.V. (1990) The 34-kilodalton membrane immunogen of Treponema pallidum is a lipoprotein. Infect Immun 58: 384-392.

Wiesmuller, K.H., Bessler, W., and Jung, G. (1983) Synthesis of the mitogenic S-(2,3-Bis(Palmitoyloxy)propryl)-N-palmitoylpentapeptide from the Escherichia coli lipoprotein. Hoppe Seylers Z Physiol Chem 364: 593-606. 
This document is a scanned copy of a printed document. No warranty is given about the accuracy of the copy. Users should refer to the original published version of the material. 